\title{
Priming Effects of Television Food Advertising on Eating Behavior
}

\author{
Jennifer L. Harris, John A. Bargh, and Kelly D. Brownell \\ Yale University
}

\begin{abstract}
Objective: Health advocates have focused on the prevalence of advertising for calorie-dense low-nutrient foods as a significant contributor to the obesity epidemic. This research tests the hypothesis that exposure to food advertising during TV viewing may also contribute to obesity by triggering automatic snacking of available food. Design: In Experiments 1a and 1b, elementary-school-age children watched a cartoon that contained either food advertising or advertising for other products and received a snack while watching. In Experiment 2, adults watched a TV program that included food advertising that promoted snacking and/or fun product benefits, food advertising that promoted nutrition benefits, or no food advertising. The adults then tasted and evaluated a range of healthy to unhealthy snack foods in an apparently separate experiment. Main Outcome Measures: Amount of snack foods consumed during and after advertising exposure. Results: Children consumed $45 \%$ more when exposed to food advertising. Adults consumed more of both healthy and unhealthy snack foods following exposure to snack food advertising compared to the other conditions. In both experiments, food advertising increased consumption of products not in the presented advertisements, and these effects were not related to reported hunger or other conscious influences. Conclusion: These experiments demonstrate the power of food advertising to prime automatic eating behaviors and thus influence far more than brand preference alone.
\end{abstract}

Keywords: food advertising, priming, eating behavior, children, obesity

According to the U.S. Surgeon General, "Obesity is the fastest growing cause of disease and death in America" (Carmona, 2003 paragraph 5). And the crisis is not unique to the U.S.; according to the World Health Organization (2003), the obesity epidemic is "a major contributor to the global burden of chronic disease and disability" (p. 1). The trend is especially disturbing among young people. Over the past 30 years, the percentage of children and adolescents in the U.S. who are overweight or at risk of becoming overweight has more than tripled to $37 \%$ and $34 \%$, respectively (Ogden et al., 2006).

This obesity crisis has been fueled by reductions in physical activity, as well as overconsumption of foods high in fat and sugar (Institute of Medicine [IOM], 2006). Health authorities believe that the accumulation of unhealthy messages communicated to children through food advertising is a leading cause of unhealthy consumption (Brownell \& Horgen, 2004; IOM, 2006). Every day, children view, on average, $15 \mathrm{TV}$ food advertisements (Federal Trade Commission, 2007), and an overwhelming 98\% of these ads promote products high in fat, sugar, and/or sodium (Powell, Szczpka, Chaloupka, \& Braunschweig, 2007). Moreover, food advertising to children portrays unhealthy eating behaviors with positive

Jennifer L. Harris, John A. Bargh, and Kelly D. Brownell, Department of Psychology, Yale University.

Acknowledgments: This research was funded in part by Grant R01MH60767 from the National Institute for Mental Health to JAB and by the Yale Rudd Center for Food Policy and Obesity. We thank Geoffrey Cohen, Becca Levy and Marlene Schwartz for their helpful comments and suggestions.

Correspondence concerning this article should be addressed to Jennifer L. Harris, Department of Psychology, Yale University, P.O. Box 208205, New Haven, CT 06520. E-mail: jennifer.harris@yale.edu outcomes. Snacking at nonmeal times occurred in $58 \%$ of food ads during children's programming (Harrison \& Marske, 2005). In addition to good taste, the most common product benefits communicated include fun, happiness, and being "cool" (Folta, Goldberg, Economos, Bell, \& Meltzer, 2006; Harrison \& Marske, 2005).

A number of reviews have examined the research on advertising to children and conclude that food advertising leads to greater preferences and purchase of the products advertised (Hastings et al., 2003; IOM, 2006; Story \& French, 2004). In addition, as assessed through correlational and quasi-experimental studies, heavier media viewing often predicts more unhealthy diets and higher body weight among children (see IOM, 2006). A few studies have also examined effects of food advertising on actual eating behaviors, usually assessed by food choices following exposure to advertising (see Hastings et al., 2003; IOM, 2006). One study with high ecological validity exposed children at an overnight camp to a daily cartoon with candy or fruit advertising, PSAs, or no ads (Gorn \& Goldberg, 1982). Over a 2-week period, children who saw the candy ads selected fruit and orange juice as a snack less often than the other children. The literature reviews also highlight, however, the need for further researchspecifically, more studies that establish a direct causal link between food advertising and unhealthy diets. To begin to address this need, Halford and colleagues recently demonstrated that groups of children eat more immediately after viewing a series of 8-10 children's food commercials than after watching commercials for other products (Halford, Boyland, Hughes, Oliveira, \& Dovey, 2007; Halford et al., 2008; Halford, Gillespie, Brown, Pontin, \& Dovey, 2004). Additionally, these effects occurred at the category level, (i.e., increased consumption transferred to foods not included in the presented advertisements). However, the au- 
thors did not obtain support for their proposed mechanism: specifically, that overweight children have greater recognition memory for food advertisements, which in turn leads to greater consumption.

The literature reviews also emphasize the need to extend food advertising research beyond children; to-date, very little is known about such effects on adolescents and adults. Finally, most research has examined advertising for calorie-dense, low-nutrient foods. As a result, we know very little about how advertising for more nutritious food affects eating behaviors. The present research addresses these gaps in our knowledge and utilizes a new approach to study food advertising effects using contemporary socialcognitive theories.

\section{Advertising as a "Real-World" Prime}

Social-cognitive theories suggest a subtle and potentially farreaching effect of food advertising on eating behaviors that may occur outside of participants' intention or awareness (i.e., unconsciously; see Bargh \& Morsella, 2008). Priming methods provide a means to test for these automatic causal effects. In priming studies, relevant mental representations are activated in a subtle, unobtrusive manner in one phase of an experiment, and then, the unconscious, unintended effects of this activation are assessed in a subsequent phase (see Bargh \& Chartrand, 2000). Priming research has already demonstrated that a variety of complex social and physical behaviors - such as aggression, loyalty, rudeness, and walking speed — can be activated by relevant external stimuli (i.e., the primes) without the person's intent to behave that way or awareness of the influence (see Dijksterhuis, Chartrand, \& Aarts, 2007). The mechanism through which behavior priming operates appears to be an overlap or strong association between representations activated by the perception of a given type of behavior, and those used to enact that type of behavior oneself (Dijksterhuis \& Bargh, 2001)-the same mechanism that creates tendencies toward imitation and mimicry in adults (Bargh, 2005; Chartrand \& Bargh, 1999) and which serves as a vital support for vicarious learning in young children (Tomasello, Carpenter, Call, Behne, \& Moll, 2005).

An important real-life source of priming influences is the media, including TV programs and advertisements. Exposure to aggressive or alcohol-consuming models in media can prime aggressive behaviors and alcohol consumption in the viewer (see Anderson \& Bushman, 2002; Roehrich \& Goldman, 1995). Studies that have focused specifically on advertising effects have shown that ads can prime positive expectancies of the effects of alcohol consumption (Dunn \& Yniguez, 1999) and positive attitudes toward smoking (Pechman \& Knight, 2002).

\section{External Cues and Consumption Behaviors}

Research among adults confirms that external cues have a significant influence on food consumption behaviors. Exposure to the sensory properties of palatable food increased subjective desire and consumption, even though participants were already fully sated (Cornell, Rodin, \& Weingarten, 1989). Subsequent studies confirmed and extended this finding, showing that exposure to sensory-related food cues increases consumption (Federoff, Polivy, \& Herman, 1997; Jansen \& van den Hout, 1991; Rogers \&
Hill, 1989). Moreover, food advertising typically focuses on the immediate sensory gratifications of consumption (i.e., the "hot," appetitive features), making resistance to these messages even more difficult (i.e., the "cold," rational process of self-restraint; Loewenstein, 1996; Metcalfe \& Mischel, 1999). In light of these findings, Lowe and Butryn (2007) proposed that palatable food stimuli can trigger hedonic hunger, or "thoughts, feelings and urges about food in the absence of energy deficits" (p. 432).

Consumption behaviors can also be activated through automatic processes. External cues, not related to the sensory qualities of food, (e.g., container size and shape, food variety, and portion size) affect amount consumed without the consumer's knowledge (Wansink, 2006). The behavior of other people is another important external behavioral cue, and people automatically mimic others' eating behaviors, including food choice and amount of food consumed, without realizing they are doing so (Johnston, 2002; Tanner, Ferraro, Chartrand, Bettman, \& van Baaren, in press). The unconscious nature of these influences is further established by studies in which primes of thirst-related words or smiling faces, presented subliminally outside of the participant's conscious awareness, increased beverage consumption among thirsty individuals (Strahan, Spencer, \& Zanna, 2002; Winkielman, Berridge, \& Wilbarger, 2005).

\section{Food Advertising}

Advertising for food and beverages communicates potentially powerful food consumption cues, including images of attractive models eating, snacking at nonmeal times, and positive emotions linked to food consumption (Folta et al., 2006; Harrison \& Marske, 2005). We propose that the messages presented in TV food advertising similarly have the power to act as real-world primes and lead to corresponding eating behaviors. Given the types of foods and consumption benefits typically promoted in food advertising, what is primed is usually snacking on unhealthy foods and beverages (Harrison \& Marske, 2005; Powell et al., 2007).

In the following studies, we experimentally test whether TV food advertising, embedded as it would naturally occur within a TV program, will prime, or directly activate, an automatic increase in snack food consumption. Because these effects are hypothesized to occur outside of conscious awareness, the intention or ability to regulate impulsive tendencies should not affect the outcome. Therefore, we predict that food advertising that conveys snacking and fun (i.e., those typically shown during children's programming) will automatically cue eating behavior among adults as well as children. In addition, in line with the Halford et al. (2004; Halford et al., 2007; Halford et al., 2008) findings, we predict that the advertising will affect consumption of any available foods, not only those that were advertised.

We designed the studies to replicate conditions in which individuals are typically exposed to food advertising on TV, as well as to minimize participant awareness that the experiments involved advertising (vs. TV viewing, in general). All advertisements were embedded within a TV program during naturally occurring commercial breaks, and the total number of food advertisements was consistent with the number typically presented during a similar amount of programming time. Experiments 1a and 1b utilized common types of children's food advertisements as stimuli and measured effects on snack food consumed by children while 
watching TV. Experiment 2 investigated the effects of both snackand nutrition-focused food advertising on adult consumption of a range of healthy to unhealthy snack foods. To further minimize awareness of the true purpose of the experiments, the advertisements were not related to the brands or types of foods to be consumed by participants.

\section{Experiments $1 \mathrm{a}$ and $1 \mathrm{~b}$}

In Experiment 1a, we tested our primary hypothesis that elementary-school-age children would consume significantly more snack food while watching a cartoon that included food advertising. In Experiment 1b, we recruited children from a more ethnically and socioeconomically diverse school district and added a participant incentive (\$20 gift card). Except where noted, recruiting and experimental procedures were identical in Experiments 1a and $1 b$.

\section{Method}

In both experiments, children were randomly assigned to watch a cartoon that included either food advertising or other types of advertising and were given a snack while watching. Children watched alone to eliminate potential imitation, social facilitation, or self-presentation effects. Parents also completed a short questionnaire with information about their child.

Participants. In total, 118 children participated: 55 in Experiment 1a and 63 in Experiment 1b; 56 girls and 62 boys; and 59 children each in the food and nonfood advertising conditions. The two conditions did not differ significantly on any of the child characteristics measured, including age, weight status, and ethnicity (all $p \mathrm{~s} \geq .16$ ). We received complete data for 108 participants; $92 \%$ of parents returned the questionnaire. Children's ages ranged from 7 to 11 years ( $M=8.8$ years). To determine children's weight status, we utilized height and weight information provided by parents and compared children's body mass index (BMI) to age- and sex-normed percentiles published by the Centers for Disease Control and Prevention (CDC, 2007). As recommended by the CDC, children with BMIs below the 5th percentile were classified as "underweight," those in the 85 th to $<95$ th percentiles were classified as "at risk of overweight," and those in the 95th or higher percentiles were classified as "overweight." Under these criteria, $3 \%$ of our participants were underweight $(n=3) ; 62 \%$ were normal weight $(n=66) ; 21 \%$ were at risk of overweight $(n=$ $23)$; and $14 \%$ were overweight $(n=15)$. There was no significant difference in children's weight status between Experiments 1a and $1 \mathrm{~b}, \chi^{2}(3, N=107)=4.52, p=.21$; and the combined rate of at-risk and overweight children (35\%) was comparable to the $37 \%$ incidence for children in the U.S. (Ogden et al., 2006).

We also obtained children's combined race/ethnicity and priorweek TV viewing from parents. Participants in Experiment 1a were primarily white, non-Hispanic (95\%), whereas our sample in Experiment 1b was ethnically diverse: $61 \%$ were white, nonHispanic $(n=39) ; 20 \%$ black, non-Hispanic $(n=13) ; 10 \%$ Hispanic $(n=6) ; 6 \%$ Asian $(n=4)$; and $2 \%$ other or mixed ethnicity $(n=1)$. According to their parents' report, children in Experiment 1a watched very little TV ( $M=1.1$ hours per day). Parents in Experiment 1b reported significantly higher child TV viewing ( $M=2.0$ hours-per-day), $t(107)=4.77, p<.01$; and that their children were more likely to have a TV in their bedrooms ( $48 \%$ vs. $4 \%$ for Experiment 1 a participants), $\chi^{2}(1, N=107)=$ 25.95, $p<.001$. In Experiment 1b, we also collected child reports of their own TV viewing: children indicated that they watched significantly more TV ( $M=3.2$ hours-per-day) than their parents reported that they watched, $t(56)=4.35, p<.001$. This level of child-reported TV viewing is comparable to the 3.2 hours-per-day reported by 8 - to 10 -year-olds in a large U.S. study that utilized a similar methodology (Roberts \& Foehr, 2004).

Procedure and materials. Parents with children in participating schools received a letter inviting them to volunteer with their children for a study to understand TV influences. In Experiment $1 \mathrm{~b}$, we also recruited six children from a summer camp in the same school district. Parents received a description of the experimental procedure. Parents who requested more information were informed that we were measuring how food advertising affects eating behaviors, but asked not to share that information with their children before the study. All parents provided written informed consent, and all procedures and materials were approved by the university's Human Subjects Committee. Participants in Experiment 1a did not receive compensation, and Experiment $1 \mathrm{~b}$ participants received a $\$ 20$ bookstore gift card.

The children met with the experimenter individually at their school or camp for approximately $30 \mathrm{~min}$. in an unoccupied classroom or conference room. For school participants, sessions were held after school. If the child asked about the purpose of the study, the experimenter informed her or him that we were interested in finding out about the kinds of things that children like, including TV shows and foods.

Following a get-acquainted activity, the children watched a 14-min. episode of "Disney's Recess," a cartoon typically viewed by 7- to 11-year-olds. In this episode, the class goes on a field trip to a science museum. One-half of the children were randomly assigned to watch a version that included four 30-s. food commercials inserted during two designated advertising breaks. These commercials promoted snack and breakfast foods of poor nutritional quality using a fun and happiness message (a high-sugar cereal, waffle sticks with syrup, fruit roll-ups, and potato chips) and were chosen to represent the types of food commercials that are most commonly shown on children's TV (Powell et al., 2007). The other half watched the same cartoon with four nonfood commercials (games and entertainment products). All commercials had aired during actual children's TV cartoon programming.

Children also received a large bowl of cheddar cheese "goldfish" crackers ( 150 gr.) and a glass of water and were told that they could have a snack while watching. (Advertising for goldfish crackers was not presented during the cartoon.) The experimenter then left the room, returned after the cartoon was finished, and asked the children when they had last eaten prior to the experiment. Participants in Experiment $1 \mathrm{~b}$ also highlighted the programs they had watched on the previous weekday and Saturday on a TV programming grid. After the children left, the experimenter weighed the remaining goldfish and recorded the amount consumed.

Separately, parents completed a short questionnaire that asked for the number of hours and minutes their child had watched TV on each of the past 7 days, whether the child has a TV in his or her bedroom, how often the child ate a snack or meal while watching TV in the past 
7 days, how much their child likes goldfish crackers, and their child's height, weight, and demographic information.

One debriefing was held for all children following completion of the sessions at their school or camp to minimize the possibility that children would share information about the purpose of the study with future participants. Interested parents also attended, and all parents received a debriefing in the mail

\section{Results}

Identical procedures were followed during the cartoon-viewing portions of Experiments $1 \mathrm{a}$ and $1 \mathrm{~b}$, and the amount of goldfish crackers consumed did not differ between the two studies ( $p=$ .68; see Table 1). Therefore, to increase the power of the statistical analyses, we combined results for the two experiments in the following analysis of eating behaviors.

As predicted, children who saw the cartoon with food advertising ate considerably more ( $45 \%$ ) goldfish crackers while watching ( $M=28.5$ gr.) than did children who saw nonfood advertising $(M=19.7$ gr. $), t(116)=3.19, p=.01, d=.60$.

It is important to note that most child characteristics did not predict or moderate consumption (see Table 1). ANOVAs were conducted with advertising condition and child categories, including weight status; gender; TV in the child's bedroom; and white, non-Hispanic versus ethnic minority as between-participants factors. All models showed a main effect of advertising condition, all $F(1,105) \geq 7.03, p<.01$. In addition, there were no significant main effects for any of the child characteristics, all $F \mathrm{~s} \leq .75, p \mathrm{~s} \geq$ .39 , and no significant interactions with advertising, all $F \mathrm{~s} \leq 1.13$, $p s \geq .29$.

Additionally, we found similar results when we conducted separate regression analyses to predict snack consumption using a standardized version of each continuous variable, a dummy variable for condition, and the interaction term. The amount of goldfish crackers consumed was not significantly correlated with amount of time since the child last ate, child's age, parents' assessment of their children's appetite, snacking while watching TV in the past week, parents' reports of their child's weekly TV viewing, or children's reported TV viewing (collected in Experiment $1 \mathrm{~b}$ only; all $p \mathrm{~s} \geq .29$ ) or with any of the interaction terms (all $p s \geq .42$ ). Only parents' assessment of how much their children liked goldfish crackers, $\beta=.20, t(3,104)=2.13, p=.04$, predicted amount consumed. Therefore, regardless of the child characteristics examined, children consumed more after viewing the food advertising.

\section{Discussion}

These results provide strong support for our hypothesis. Children who saw food advertising ate $8.8 \mathrm{~g}$. more during the $14 \mathrm{~min}$. they watched TV in this experiment. At this rate, snacking while watching commercial TV with food advertisements for only 30 min. per day would lead to 94 additional kcal. consumed and a weight gain of almost 10 pounds per year, if not compensated by reduced consumption of other foods or increased physical activity.

Unexpectedly, of the child characteristics measured, only liking of goldfish crackers (as reported by parents) predicted amount consumed. We caution against making definitive conclusions about differences in eating behaviors between different groups of children, as some parent and child reports, including child's weight and TV viewing, may be biased. However, the lack of significant moderating effects for any of the child characteristics measured suggests the considerable power of food advertising to consistently influence consumption across a highly diverse sample of children. In general, then, the effect of food advertising was consistent with an automatic link between perception and behavior and in line with most other recent demonstrations of behavioral priming effects (Dijksterhuis \& Bargh, 2001; Dijksterhuis et al., 2007).

\section{Experiment 2}

In Experiment 2, we expand on the above findings to predict that food advertising will also prime eating behavior among an adult sample. In addition, we examine whether effects on eating behavior are simply due to exposure to images and thoughts of palatable foods or whether the product benefits presented in the advertising differentially affect consumption. Specifically, we hypothesize that exposure to food advertising that promotes snacking, fun, and excitement will prime greater consumption of snack foods than advertising that conveys nutrition benefits. Although we did not

Table 1

Goldfish Cracker Consumption and Advertising Effects by Child Characteristics in Experiments 1a and 1b Combined (Unless Noted)

\begin{tabular}{|c|c|c|c|c|c|}
\hline \multirow[b]{3}{*}{ Group 1} & \multicolumn{2}{|c|}{ Amount Consumed (gr.) } & \multirow[b]{3}{*}{ Group 2} & \multicolumn{2}{|c|}{ Amount Consumed (gr.) } \\
\hline & Other Ads & Food Ads & & Other Ads & Food Ads \\
\hline & $M(S E)$ & $M(S E)$ & & $M(S E)$ & $M(S E)$ \\
\hline Experiment 1a $(n=52)$ & $19.5(3.0)$ & $30.4(3.0)$ & Experiment $1 \mathrm{~b}(n=66)$ & $19.9(2.6)$ & $27.0(2.6)$ \\
\hline Boys $(n=58)$ & $19.0(2.6)$ & $30.5(3.0)$ & Girls $(n=51)$ & $20.6(3.2)$ & $25.9(2.9)$ \\
\hline TV in bedroom $(n=31)$ & $17.8(4.1)$ & $26.4(3.7)$ & No TV in bedroom $(n=78)$ & $20.3(2.3)$ & $28.8(2.5)$ \\
\hline Under- or normal weight $(n=69)$ & $19.4(2.7)$ & $27.7(2.6)$ & At risk or over-weight $(n=38)$ & $20.3(3.4)$ & $28.9(3,7)$ \\
\hline White, non-Hispanic $(n=82)$ & $19.6(2.7)$ & $30.7(2.6)$ & Ethnic minority $(n=26)$ & $17.8(4.6)$ & $25.9(4.8)$ \\
\hline $7-8$ years old $(n=41)$ & $18.1(3.7)$ & $30.3(3.1)$ & $9-11$ years old $(n=65)$ & $20.1(2.5)$ & $26.8(2.9)$ \\
\hline $\begin{array}{l}\text { TV viewing (parent report): Less than } \\
10 \text { hours per week }(n=53)\end{array}$ & $20.0(2.8)$ & $30.5(3.1)$ & $\begin{array}{l}\text { TV viewing (parent report): } \\
10+\text { hours per week }(n=52)\end{array}$ & $19.3(2.9)$ & $26.1(2.8)$ \\
\hline $\begin{array}{l}\text { TV viewing (child report): Less than } 3 \\
\text { hours per day }(n=27)^{\dagger}\end{array}$ & $19.3(4.5)$ & $28.2(5.0)$ & $\begin{array}{l}\text { TV viewing (child report): } 3+\text { hours } \\
\text { per day }(n=30)^{\dagger}\end{array}$ & $20.8(4.6)$ & $28.3(4.3)$ \\
\hline
\end{tabular}

Collected in Experiment $1 \mathrm{~b}$ only. 
specifically test the effects of advertising for different types of foods, these messages are commonly used to promote caloriedense, low-nutrient food products in both adult and children's food advertising (Harrison \& Marske, 2005), whereas the nutrition message tends to be used in advertising for somewhat healthier products. Finally, we examine individual differences in food advertising effects. Prior research has demonstrated that women who habitually diet and monitor their weight (i.e., restrained eaters) may be especially prone to increased eating when exposed to external food cues (Federoff et al., 1997; Jansen \& van den Hout, 1991). As a result, we hypothesize a general effect of snack advertising on increased eating, but a more pronounced effect on restrained eaters.

\section{Method}

As in the first experiments, we attempted to replicate viewing conditions in which participants would be naturally exposed to food advertising. In Experiment 2, however, participants were not provided with a snack while watching. Instead, they were asked to participate in an ostensible "second experiment" to test consumer products. In this second study, they tasted and rated snack foods that varied in perceived nutritional value.

Participants. Participants were 98 university students between 18 and 24 years old. Restrained eaters (i.e., those with scores $\geq 15$ on the Eating Restraint Scale; Herman, Polivy, Pliner, Threlkeld, \& Munic, 1978) included 31 women and 8 men; unrestrained eaters included 29 women and 24 men. Participants were racially and ethnically diverse: $61 \%$ were of white, European American descent only $(n=55) ; 7 \%$ were black only $(n=7)$; $14 \%$ Asian only $(n=13) ; 7 \%$ Hispanic only $(n=6)$; and $9 \%$ mixed race or ethnicity $(n=9)$. Participants received introduction to psychology course credit or $\$ 10$.

Materials. A 16-min., abbreviated version of an improvisational comedy TV program ("Whose Line is it Anyway?") was used as the TV-viewing stimuli. The program included $11 \mathrm{com}-$ mercials (4 min. total), inserted during two commercial breaks. Three versions were created; each version included seven of the same nonfood commercials. In addition, one version included four commercials for food and beverages with a snacking message that emphasized fun and excitement (two fast-food products, candy bar, and cola soft drink); another included four food and beverage commercials with a nutrition message (granola bar, orange juice, oatmeal, and an "instant breakfast" beverage); and the control included four additional nonfood commercials. These commercials were inserted into nonprominent positions during the commercial break (i.e., not the first or last commercial) to reduce the likelihood that participants would pay more than their usual amount of attention to the food commercials.

Pretesting with a sample of college students confirmed that the food advertisements communicated the intended product benefits (see Table 2). The commercials were also matched on other persuasion-related characteristics. Pretest participants reported similar moderate levels of enjoyment for all commercials $(M=$ 5.59 out of 10 for the snack ads, 5.53 for the nutrition ads, and 5.05 for the control ads), $F(2,158)=1.20$, ns. In addition, past consumption of the foods in the snack and nutrition ads did not differ significantly ( $M=1.78$ out of 6 for the snack ads and 2.11 for the nutrition ads $), t(102)=1.37, n s$; nor did future intent to purchase the foods $(M=4.78$ out of 10 for the snack ads; $M=$ 5.20 for the nutrition ads), $t(102)=1.37, n s$. The only significant difference found was that participants were less familiar with the nutrition commercials $(M=1.13$ out of 6$)$ than the snack $(M=$ $1.47)$ or control $(M=1.68)$ commercials, $F(2,158)=6.91, p<$ .01. Familiarity was low, however, for all commercials tested.

Procedures. All participants were tested between 3:00 and 6:00 p.m. to minimize initial differences in hunger. On average, participants had last eaten 2.8 hours earlier $(S D=2.5)$. They were informed that the first study examined effects of TV on mood and were randomly assigned to watch one of the three versions of the TV program. To increase the believability of the cover story, participants were informed that they were in the "comedy condition," and that the experimenter had kept the commercials to make the viewing experience as realistic as possible. Before and after watching TV, participants completed a PANAS current mood assessment (Watson, Clark, \& Tellegen, 1988). To assess hunger without alerting participants that the study involved food, hunger and thirst ratings were embedded within the PANAS assessment. As with the mood measures, participants responded on a scale from 1 (very slightly/not at all) to 5 (extremely) in response to "How hungry/thirsty do you feel right now, at this present moment?" All participants watched in a small, comfortable room, by themselves.

In line with the cover story, participants were then asked to move to another room, with a different experimenter. They were

Table 2

Advertising Pre-Test Results: Assessment of Product Benefits Communicated in Food Advertisements

\begin{tabular}{|c|c|c|c|c|c|}
\hline \multirow[b]{2}{*}{ Product benefits communicated } & \multicolumn{2}{|c|}{ Snack ads $(n=49)$} & \multicolumn{2}{|c|}{ Nutrition ads $(n=55)$} & \multirow{2}{*}{$\frac{\text { Comparison }}{X^{2}(2, N=104)}$} \\
\hline & Main benefit & Any benefit & Main benefit & Any benefit & \\
\hline Nutritious or healthy & $0 \%$ & $2.0 \%$ & $40.0 \%$ & $90.9 \%$ & $81.95^{* * *}$ \\
\hline All natural & $0 \%$ & $2.0 \%$ & $16.4 \%$ & $49.1 \%$ & $29.42^{* * * *}$ \\
\hline Good for snacking & $40.8 \%$ & $71.4 \%$ & $1.8 \%$ & $10.9 \%$ & $81.95^{* * *}$ \\
\hline Exciting or fun & $26.5 \%$ & $71.4 \%$ & $1.8 \%$ & $18.2 \%$ & $41.43^{* * * *}$ \\
\hline Tastes good & $57.1 \%$ & $81.6 \%$ & $20.0 \%$ & $67.3 \%$ & $15.27^{* * * *}$ \\
\hline Convenient & $6.1 \%$ & $30.6 \%$ & $1.8 \%$ & $23.6 \%$ & .47 \\
\hline Gives you energy & $10.2 \%$ & $22.4 \%$ & $20.0 \%$ & $45.5 \%$ & $6.07^{*}$ \\
\hline
\end{tabular}

${ }^{*} p<.05 . \quad{ }^{* * * *} p<.001$. 
seated at a table with five premeasured snack foods, including very healthy (carrots and celery with dip), calorie-dense, nutrient-poor items (mini chocolate chip cookies and cheesy snack mix), and items perceived to be moderately healthy (trail mix and multigrain tortilla chips). They also received a bottle of water. Until this point, participants were not aware that the study involved food. As in the prior experiments, none of the snack foods tested had been advertised during the TV segment. Participants were instructed to take at least one bite of each and rate it on a variety of dimensions but also told they could eat as much as they liked. The experimenter then left the room.

After the participants finished the tasting, they informed the experimenter, who removed the food items and asked them to complete questionnaires to assess perceived healthiness of the foods tasted, restrained eating, and demographics. These items were assessed at the end of the session to avoid affecting eating behaviors with reminders of health or dieting (other than those presented in the advertisements). The weight of each food consumed was recorded, as well as the total amount of time spent eating. Finally, the first experimenter conducted a funnel debriefing (Bargh \& Chartrand, 2000) to probe for awareness of the experimental hypotheses and effect of the advertisements on subsequent eating behavior. Unaided recall of specific advertisements was also obtained during the debriefing.

\section{Results and Discussion}

During the funnel debriefing, most participants indicated that they had noticed the advertising, but believed our cover story that the study involved TV and mood. To ensure that the following analyses demonstrate effects of food advertising that occurred outside of participants' awareness, however, we eliminated the data for the few participants (four each in the snack and nutrition advertising conditions) who correctly guessed that the study concerned effects of food commercials on eating behaviors or who believed that the food commercials might have influenced what or how much they ate.

As intended, participants rated the cookies and snack mix as very unhealthy ( $M=2.71$ out of 10 and 2.31 , respectively), the vegetables as very healthy $(M=7.71)$, and the trail mix $(M=$ 4.92) and multigrain chips $(M=4.92)$ as in between. In addition, participants reported fairly high taste ratings for all the foods, with the lowest ratings for the multigrain chips ( $M=6.46$ out of 10$)$ and the highest ratings for the vegetables $(M=7.64)$ and cookies $(M=7.70)$.

Advertising effects on consumption. Participants ate the most vegetables ( $M=34.3$ gr.; vegetables also weighed the most), followed by cookies $(M=17.9$ gr. $)$, trail mix $(M=12.3$ gr.), snack mix $(M=9.4$ gr.), and multigrain chips ( $M=7.2$ gr.). To adjust for weight differences in the foods, we computed $z$-scores for amount of each food consumed and averaged the standardized scores to obtain a single food-consumption score for each participant. According to this measure, a positive score indicates a total consumed of " $X$ " standard deviations above the sample mean, and a negative score indicates a lower-than-average amount consumed.

To control for potential individual differences in our dependent variables, we conducted all analyses using ANOVAs with advertising condition, gender, and restrained eating as betweenparticipants factors. As predicted, the main effect of advertising condition was significant, such that participants who saw snack ads ate more $(M=.51)$ than did control participants $(M=.07)$ or those who saw nutrition ads $(M=-.13), F(2,78)=3.72, p=.03$, $\eta^{2}=.09$. An ANOVA to predict eating time also showed a main effect of advertising, $F(2,78)=5.05, p<.01, \eta^{2}=.12$. Again, participants who saw snack ads ate for the longest amount of time ( $M=13.1 \mathrm{~min}$.) compared to the other participants $(M=9.8 \mathrm{~min}$. for the control and $M=8.7 \mathrm{~min}$. for nutrition ads).

Planned comparisons of the two types of food ads to each other and the control confirmed that participants who viewed the snack ads consumed significantly more than those who viewed the nutrition ads, $F(1,49)=8.57, p<.01, \eta^{2}=.15$, and the difference in consumption between snack ads and the control approached conventional significance, $F(1,51)=3.24, p=.08, \eta^{2}=.06$. The difference between nutrition ads and the control was not significant $(p=.30)$.

As predicted, there was a trend for restrained eaters to eat more overall than unrestrained eaters $(M=.31$ vs. -.01$), F(1,78)=$ $3.34, p=.07, \eta^{2}=.04$. Men also ate considerably more than women $(M=.50$ vs. -.20$), F(1,78)=15.05, p<.001, \eta^{2}=.16$. The Advertising $\times$ Restrained Eating interaction approached significance, $F(2,78)=2.75, p=.07, \eta^{2}=.07$, and the Advertising $\times$ Gender interaction was reliable, $F(2,78)=3.25, p=.04$, $\eta^{2}=.08$ (see Figure 1). The snack advertising had powerful effects on men and restrained eaters, with both groups consuming approximately one $S D$ more after exposure to snack ads versus
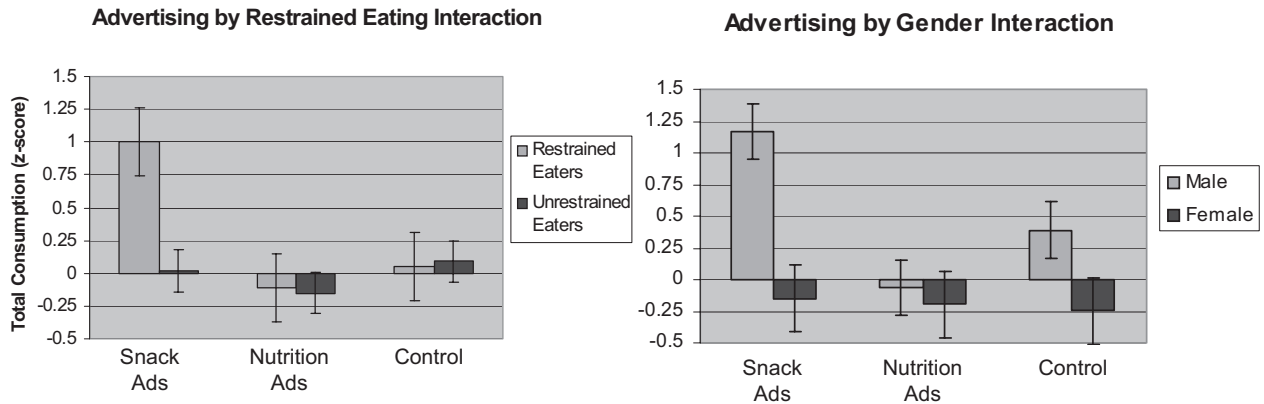

Figure 1. Interaction effects between advertising message and eating restraint and gender on total food consumed. 
nutrition ads or no food ads. Female unrestrained eaters, however, ate similar amounts across all conditions.

Potential mediators and moderators of the effects. We then examined whether the effects of advertising on consumption behavior were mediated by hunger or mood. ANOVAs to predict change in hunger and mood (before and after viewing) showed no main effects of advertising ( $p s \geq .58$ ) or interaction effects on change in $\operatorname{mood}(p s \geq .50)$. The 2 -way interactions between advertising and both gender and restrained eating on change in hunger were significant, $F(2,78)=3.68, p=.03, \eta^{2}=.09$ and $F(2,78)=2.86, p=.06, \eta^{2}=.06$, but these effects were opposite those found for consumption behaviors. Restrained eaters and men reported feeling less hungry after viewing snack advertising $(M=$ -.41 and -.44$)$ and more hungry after viewing nutrition advertising $(M=.44$ and .54$)$, indicating a complete dissociation between reported hunger and eating behaviors.

We also examined potential predictors and moderators of total consumption, including hunger and mood at the time participants arrived at the experiment (Time 1) and after they had watched the TV program (Time 2), as well as the number of commercials recalled (awareness). Again, ANCOVAs to predict total consumption using hunger, mood, and awareness variables as covariates showed no significant relationship to amount consumed (all $p s \geq .20$ ). Only one interaction between these potential moderator variables and advertising condition approached significance: advertising and hunger at Time 2, F(2, $78)=2.61, p=.08, \eta^{2}=.06$, (all other $p s \geq .16$ ). Further analyses revealed that hunger immediately prior to eating was related to amount consumed only for participants who had viewed nutrition advertising $(r=.57, p<.01)$. Hunger was not, however, significantly related to amount consumed for participants in the snack ads and control conditions $(r s<.10$, $p s \geq .59$ ). These findings further support the direct influence of the snack advertising on consumption, as effects were unmediated by subjective internal states like hunger.

Finally, we examined the relationship between taste and healthiness ratings and actual consumption for individual foods. Taste ratings were positively correlated with amount consumed for all foods (ranging from $r=.23, p<.05$ for vegetables to $r=.45, p<.01$ for snack mix), but perceived healthiness was related only to the amount of vegetables consumed, $r=.21$, $p<.05$ (all other $r \mathrm{~s} \leq \pm .10, p \mathrm{~s} \geq .34$ ). ANCOVAs to predict amount consumed of individual foods, using rated taste of that food as a covariate, demonstrated significant main effects of advertising on cookie, $F(2,76)=4.01, p=.02, \eta^{2}=.10$, and multigrain chip consumption, $F(2,76)=11.46, p<.001, \eta^{2}=$ .23. In all cases, however, the direction of influence was the same. Participants who saw snack commercials ate the most of every food, regardless of healthiness, and those who saw nutrition commercials ate the least (see Figure 2).

Discussion. Experiment 2 demonstrates that adults are also susceptible to the automatic effects of food advertising on consumption behavior. ${ }^{1}$ These effects were extremely powerful for men and restrained eaters. We also demonstrated that the influence of the snack ads continued after exposure (such that they carried over to the subsequent "second experiment"), and that participants were not aware that they were affected. In addition, as in the children's experiments, advertising effects could not be accounted for by participants' hunger, and the effects transferred to products that were not advertised during the TV segments viewed by the participants. Snack advertising also increased consumption of healthier snack options, including vegetables, further supporting the automatic nature of the advertising effects.

In contrast, food advertising with a nutrition message appeared to inhibit automatic consumption, as evidenced by the relationship between hunger and consumption only for participants in the nutrition advertising condition. Nutrition-focused advertising did not, however, affect the healthiness of food consumed.

\section{General Discussion}

These experiments provide converging evidence of an automatic, direct causal link between food advertising and greater snack consumption, and further contradict industry claims that advertising affects only brand preferences and not overall nutrition (Young, 2003). Overall, the findings were highly consistent. In both studies, and across diverse populations, food advertising that promoted snacking, fun, happiness, and excitement (i.e., the majority of children's food advertisements) directly contributed to increased food intake. In addition, as previously found by Halford et al. (2004; Halford et al., 2007; Halford et al., 2008), similarity between the foods provided and those advertised was not required. Finally, these effects occurred regardless of participants' initial hunger, and amount consumed after viewing snack advertising was completely dissociated with adult participants' reported hunger.

The potential health consequences of these naturally occurring advertising priming effects on overall diet and attempts to control unhealthy eating are far-reaching. Children may be most consistently affected, yet snack advertising also increased adult consumption, especially for men and those attempting to diet. In addition, the effects persisted after the viewing session. Therefore, it may not be possible for one to avoid influence simply by not snacking while watching TV; TV viewing could also lead to increased consumption during a subsequent snack or meal.

One limitation of our findings (as with most laboratory experiments) is that real-world exposure to advertising stimuli occurs in a wide variety of contexts, and we cannot be certain that other situational factors (e.g., viewing with others, viewing at other times of the day, or viewing for other purposes) would not have moderated the advertising effects. To optimize both external and internal validity, however, we imitated natural $\mathrm{TV}$-viewing conditions as closely as possible within a controlled setting. We feel confident, therefore, that the increased snacking was due to the advertising, and that these effects do occur during real-world viewing.

\section{Potential Mechanisms}

Although our findings are consistent with a number of potential priming mechanisms, the specific mechanisms through which food advertising increased automatic eating behavior cannot be identified with certainty. As many potential interven-

\footnotetext{
${ }^{1}$ Although we did not obtain food advertising awareness in the first experiments, we assume that children would be, if anything, less aware than adults that food advertising might affect their consumption behaviors
} 

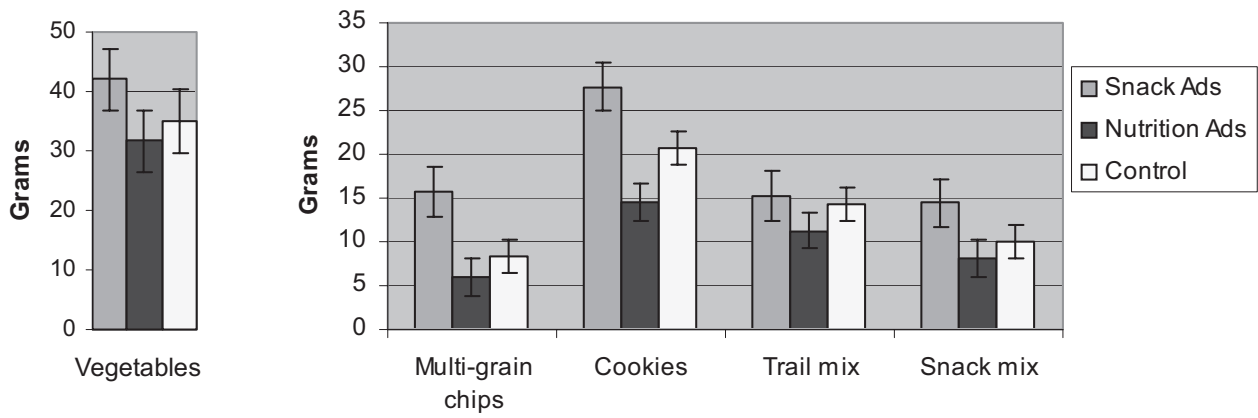

Figure 2. Main effects of advertising message on amount consumed for individual foods (controlling for taste ratings).

ing variables did not moderate the advertising-eating effects, much of the effect probably occurred directly upon perceiving the eating behavior of people in the ads and/or activating concepts associated with consumption (e.g., Dijksterhuis \& Bargh, 2001). A motivational explanation is also quite viable (Bargh, Gollwitzer, Lee-Chai, Barndollar, \& Troetschel, 2001; Shah \& Kruglanski, 2002). Snack advertising may have primed a short-term hedonic enjoyment goal, whereas nutrition advertising primed a long-term goal of healthy eating, leading to corresponding behaviors. In reality, the power of advertising may be its ability to prime behaviors through multiple mechanisms at the same time.

Another limitation of our findings is that we cannot pinpoint the specific advertising features that affected eating behaviors. To increase the ecological validity of the findings, we utilized actual advertising stimuli. As a result, the stimuli may have conflated the benefits promoted in the ads (i.e., snacking, fun, and excitement vs. nutrition) with positive associations toward the types of foods typically promoted in ads with those messages (i.e., nutrient-poor foods vs. "healthier" options). Our findings suggest, however, that the effect of priming product benefits was more powerful than the effect of priming specific types of foods: The snack ads increased consumption of all foods, including the healthier options, and the nutrition message did not increase consumption of the healthier foods (in fact, consumption of all foods was lowest in this condition). Further research is required to confirm that priming snacking versus nutrition benefits and not other features of the advertisements, including specific types of foods or brands, triggered the effects on consumption behaviors. In addition, the messages used to frame food consumption in advertising are also likely to create powerful effects on consumption, and these could be profitably examined in future research.

\section{Defending Against Advertising Influence}

Further understanding of the mechanisms that produced these priming effects is also needed to enable educators and parents to more effectively protect children (and themselves) against unhealthy food advertising influence. Wilson and Brekke (1994) proposed that defense against unconscious "mental contamination" requires awareness and understanding of how unwanted external influences might affect us, as well as the motivation and ability to defend against influence. As most adults in our study did not recognize the potential influence of food advertising on their eating behaviors, increased awareness will be an important first step. These findings also highlight the need for media literacy programs that go beyond teaching children how to analyze and evaluate advertising messages and increase the public's understanding of how advertising may affect them outside of their awareness (Livingstone \& Helsper, 2006).

Additional studies could also examine contexts that might affect motivation and ability to defend against food advertising priming effects. According to Baumeister and colleagues, selfregulatory resources are limited and can become depleted and unavailable for subsequent self-regulatory tasks (Muraven \& Baumeister, 2000). Food advertising effects could be especially pronounced, therefore, in the evening "prime-time" hours when most adult TV viewing occurs, following a day of self-control efforts. Perhaps, under such ego-depletion or cognitive load conditions, snack advertising might also affect female unrestrained eaters. Additional studies could also examine whether advertising that utilizes other consumption messages (e.g., satisfaction or indulgence) would differentially affect motivations to consume.

Another important direction for future research will be to examine the priming effects of other forms of food advertising. Increasingly, food companies are replacing TV advertising with more subtle marketing strategies (Chester \& Montgomery, 2007). Future studies could examine whether consumption behaviors modeled during TV programming and movies (through product placements) or interactive websites involving food products also prime automatic consumption behaviors. Other priming studies suggest that even exposure to less overt food cues (e.g., brand logos that appear on signs or websites) could affect food consumption (e.g., Strahan et al., 2002; Winkielman et al., 2005).

In summary, our results demonstrate that TV food advertising increases snack consumption and may contribute to the obesity epidemic, and that efforts to reduce unhealthy food advertising to children are urgently needed. In addition, they highlight the need to increase awareness of the potential automatic effects of food advertising on eating behavior. Current industry efforts to self-regulate TV food advertising to youth are limited to children 12 years and under (Council of Better Business Bureaus, 2006), but the present findings suggest that reduced exposure to unhealthy food advertising would be beneficial for all age groups. 


\section{References}

Anderson, C. A., \& Bushman, B. J. (2002). The effects of media violence on society. Science, 295, 2377-2379.

Bargh, J. A. (2005). Bypassing the will: Towards demystifying behavioral priming effects. In R. Hassin, J. Uleman, \& J. Bargh (Eds.), The new unconscious. Oxford, England: Oxford University Press.

Bargh, J. A., \& Chartrand, T. L. (2000). The mind in the middle: A practical guide to priming and automaticity research. In H. T. Reis \& C. M. Judd (Eds.), Handbook of research methods in social and personality psychology (pp. 253-285). New York: Cambridge University Press.

Bargh, J. A., Gollwitzer, P. M., Lee-Chai, A. Y, Barndollar, K., \& Troetschel, R. (2001). The automated will: Nonconscious activation and pursuit of behavioral goals. Journal of Personality and Social Psychology, 81, 1014-1027.

Bargh, J. A., \& Morsella, E. (2008). The unconscious mind. Perspectives on Psychological Science, 3, 73-79.

Brownell, K. D., \& Horgen, K. B. (2004). Food fight: The inside story of the food industry, America's obesity crisis, and what we can do about it. New York: McGraw-Hill.

Carmona, R. H. (2003). Testimony before the Subcommittee on Education Reform Committee on Education and the Workforce U.S. House of Representatives: The obesity crisis in America. Retrieved August 30, 2007, from http://www.surgeongeneral.gov/news/testimony/obesity07162003.htm

Centers for Disease Control and Prevention. (2007). About BMI for Children and Teens. Retrieved August 15, 2007, from http://www.cdc.gov/ nccdphp/dnpa/bmi/childrens_BMI/about_childrens_BMI.htm

Chartrand, T. L., \& Bargh, J. A. (1999). The chameleon effect: The perception-behavior link and social interaction. Journal of Personality and Social Psychology, 76, 893-910.

Chester, J., \& Montgomery, K. (2007). Interactive food and beverage marketing: Targeting children and youth in the digital age. Retrieved September 10, 2007, from http://digitalads.org

Cornell, C. E., Rodin, J., \& Wingarten, H. (1989). Stimulus-induced eating when satiated. Physiology and Behavior, 45, 695-704.

Council of Better Business Bureaus. (2006, November 14). New food, beverage initiative to focus kids' ads on healthy choices; Revised guidelines strengthen CARU's guidance to food advertisers [Press release]. Retrieved August 16, 2007, from http://www.bbb.org/alerts/article .asp? ID $=728$

Dijksterhuis, A., \& Bargh, J. A. (2001). The perception-behavior expressway: Automatic effects of social perception on social behavior. In M. P. Zanna (Ed.), Advances in experimental social psychology (Vol. 33, pp. 1-40). San Diego: Academic Press.

Dijksterhuis, A., Chartrand, T. L., \& Aarts, H. (2007). Automatic behavior. In J. A. Bargh (Ed.), Social psychology and the unconscious: The automaticity of higher mental processes (pp. 51-131). Philadelphia: Psychology Press.

Dunn, M. E., \& Yniguez, R. M. (1999). Experimental demonstration of the influence of alcohol advertising on the activation of alcohol expectancies in memory among fourth- and fifth-grade children. Experimental and Clinical Psychopharmacology, 7, 473-483.

Federal Trade Commission. (2007). Bureau of Economics staff report: Children's exposure to TV advertising in 1977 and 2004. Retrieved October 22, 2007, from http://www.ftc.gov

Federoff, I., Polivy, J., \& Herman, C. P. (1997). The effect of pre-exposure to food cues on the eating behavior of restrained and unrestrained eaters. Appetite, 28, 33-47.

Folta, S. C., Goldberg, J. P., Economos, C., Bell, R., \& Meltzer, R. (2006). Food advertising targeted at school-age children: A content analysis. Journal of Nutrition Education and Behavior, 38, 244-248.

Gorn, G. J., \& Goldberg, M. E. (1982). Behavioral evidence of the effects of televised food messages on children. Journal of Consumer Research, 9, 200-205.

Halford, J. C. G., Boyland, M. J., Hughes, G., Oliveira, L. P., \& Dovey, T. M. (2007). Beyond-brand effect of television (TV) food advertise- ments/commercials on caloric intake and food choice of 5-7-year-old children. Appetite, 49, 263-267.

Halford, J. C. G., Boyland, E. J., Hughes, G. M., Stacey, L., McKean, S., \& Dovey, T. M. (2008). Beyond-brand effect of television food advertisements on food choice in children: The effects of weight status. Public Health Nutrition, 897-904.

Halford, J. C. G., Gillespie, J., Brown, V., Pontin, E. E., \& Dovey, T. M. (2004). Effect of television advertisements for foods on food consumption in children. Appetite, 42, 221-225.

Harrison, K., \& Marske, A. L. (2005). Nutritional content of foods advertised during the television programs children watch most. American Journal of Public Health, 95, 1568-1574.

Hastings, G., Stead, M., McDermott, L., Forsyth, A., MacKintosh, A. M., Rayner, M., et al. (2003). Review of research on the effects of food promotion to children. Retrieved February 20, 2006, fromhttp:// www.foodstandards.gov.uk/multimedia/pdfs/foodpromotiontochildren1.pdf

Herman, C. P. Polivy, J., Pliner, P., Threlkeld, J., \& Munic, D. (1978), Distractibility in dieters and nondieters: An alternative view of externality. Journal of Personality and Social Psychology, 36, 536-548.

Institute of Medicine (2008). National Academy of Sciences, Committee on Food Marketing and the Diets of Children and Youth. Food Marketing to Children and Youth: Threat or Opportunity? J. M. Mcginnis, J. Gootman, \& V. I. Kraak (eds.). Washington, DC: National Academies Press.

Jansen, A., \& van den Hout, M. (1991). On being led into temptation: "Counterregulation" of dieters after smelling a "preload." Addictive Behaviors, 16, 247-253.

Johnston, L. (2002). Behavioral mimicry and stigmatization. Social Cognition, 20, 18-35.

Livingstone, S., \& Helsper, E. J. (2006). Does advertising literacy mediate the effects of advertising on children? A critical examination of two linked research literatures in relation to obesity and food choice. Journal of Communication, 56, 560-584.

Loewenstein, G. (1996). Out of control: Visceral influences on behavior. Organizational and Human Decision Processes, 65, 272-292.

Lowe, M. R., \& Butryn, M. L. (2007). Hedonic hunger: A new dimension of appetite. Physiology and Behavior, 91, 432-439.

Metcalfe, J., \& Mischel, W. (1999). A hot/cool system analysis of delay of gratification: Dynamics of willpower. Psychological Bulletin, 100, 3-19.

Muraven, M., \& Baumeister, R. F. (2000). Self-regulation and depletion of limited resources: Does self-control resemble a muscle?. Psychological Bulletin, 126, 247-259.

Ogden, C. L., Carroll, M. D., Curtin, L. R., McDowell, M. A., Tabak, C. J., \& Flegal, K. M. (2006). Prevalence of overweight and obesity in the U. S., 1999-2004. Journal of the American Medical Association, 295(13), 1549-1555.

Pechmann, C., \& Knight, S. J. (2002). An experimental investigation of the joint effects of advertising and peers on adolescents' beliefs and intentions about cigarette consumption. Journal of Consumer Research, 29, 5-19.

Powell, L. M., Szczpka, G., Chaloupka, F. J., \& Braunschweig, C. L. (2007). Nutritional content of television food advertisements seen by children and adolescents. Pediatrics, 120, 576-583.

Roberts, D. F., \& Foehr, U. G. (2004). Kids \& Media in America. Cambridge, UK: Cambridge University Press.

Roerich, L., \& Goldman, M. S. (1995). Implicit priming of alcohol expectancy memory processes and subsequent drinking behavior. Experimental and Clinical Psychopharmacology, 3, 402-410.

Rogers, P. J., \& Hill, A. J. (1989). Breakdown of dietary restraint following mere exposure to food stimuli: Interrelationships between restraint, hunger, salivation and food intake. Addictive Behaviors, 14, 387-397.

Shah, J. Y., \& Kruglanski, A. W. (2002). Priming against your will: How accessible alternatives affect goal pursuit. Journal of Experimental Social Psychology, 38, 384-396. 
Story, M., \& French, S. (2004). Food advertising and marketing directed at children and adolescents in the U.S. International Journal of Behavioral Nutrition and Physical Activity, 1, 3.

Strahan, E. J., Spencer, S. J., \& Zanna, M. P. (2002). Subliminal priming and persuasion: Striking while the iron is hot. Journal of Experimental Social Psychology, 38, 556-568.

Tanner, R. J., Ferraro, R., Chartrand, T. L., Bettman, J. R., \& van Baaren, $\mathrm{R}$. (in press). Of chameleons and consumption: The impact of mimicry on choice and preferences. Journal of Consumer Research.

Tomasello, M., Carpenter, M., Call, J., Behne, T., \& Moll, H. (2005). Understanding and sharing intentions: The origins of cultural cognition. Behavioral and Brain Sciences, 28, 675-735.

Wansink, B. (2006). Mindless eating: Why we eat more than we think. New York: Bantam Books.

Watson, D., Clark, L. A., \& Tellegen, A. (1988). Development and validation of brief measures of positive and negative affect: The PANAS scales. Journal of Personality and Social Psychology, 54, 1063-1070.

Wilson, T. D., \& Brekke, N. (1994). Mental contamination and mental correction: Unwanted influences on judgments and evaluations. Psychological Bulletin, 116, 117-142.

Winkielman, P., Berridge, K. C., \& Wilberger, J. L. (2005). Unconscious affective reactions to masked happy versus angry faces influence consumption behavior and judgments of value. Personality and Social Psychology Bulletin, 31, 121-235.

World Health Organization. (2003). Obesity and overweight fact sheet. Retrieved September 1, 2007, from http://www.who.int/dietphysicalactivity/ media/en/gsfs_obesity.pdf

Young, B. (2003). Does food advertising make children obese? International Journal of Advertising \& Marketing to Children, 4, 19-26.

\section{Correction to Lehman, Taylor, Kiefe, and Seeman (2009)}

In the article "Relationship of Early Life Stress and Psychological Functioning to Blood Pressure in the CARDIA Study" by Barbara J. Lehman, Shelley E. Taylor, Catarina I. Kiefe, and Teresa E. Seeman (Health Psychology, 2009, Vol. 28, No. 3, pp. 338-346), a URL for supplemental materials was included due to a production error. There are no supplemental materials for this article. 